\title{
Improving Survey Measures of Household Inflation Expectations
}

\author{
Wändi Bruine de Bruin, Simon Potter, Robert Rich, \\ Giorgio Topa, and Wilbert van der Klaauw
}

Expectations about future inflation are generally thought to play an important role in households' decisions about spending and saving. They are also of great interest to central bankers, who take them into account when determining policy or assessing the effectiveness of communications with the public. To help improve existing survey measures of inflation expectations, the Federal Reserve Bank of New York recently joined with other institutions and academic consultants to develop a set of survey questions that will yield more reliable information on households' inflation expectations, inflation uncertainty, and expectations about future wage changes.

A wide range of household decisions - whether to purchase a home, to save, or to take out a student loan - can be affected by expectations about future inflation. Measures of inflation expectations, and the degree of uncertainty attached to expectations, are of direct interest to policymakers, who track and forecast economic conditions.

Indeed, inflation expectations play an important role in modern monetary policy. Federal Reserve Chairman Ben Bernanke (2007) has argued that accurate and consistent measures of inflation expectations are important for calibrating monetary policy and deepening the Fed's understanding of economic behavior.

People's expectations about inflation — and hence inflation itself-are determined in large part by how they believe the central bank will conduct monetary policy. For that reason, central banks communicate explicit or quasi-explicit inflation targets to help "anchor" the public's long-run expectations about inflation.

For several decades, economists have relied on surveys to measure these expectations. However, relatively little is known about how respondents interpret the survey questions, how their interpretation affects their responses, and how much their expectations influence their behavior and beliefs about the economy.

A major source of information on U.S. households' inflation expectations is the Reuters/ University of Michigan Survey of Consumers. Often referred to as "the Michigan Survey," it randomly surveys a nationally representative sample of about 500 households each month. In addition to asking questions about current economic conditions, the survey solicits yearahead and five-to-ten-year-ahead forecasts for expected changes to "prices in general." These questions have remained essentially unchanged for thirty years.

Given the importance of inflation expectations, the Federal Reserve Bank of New York, in collaboration with the Federal Reserve Bank of Cleveland and other partners, initiated the Household Inflation Expectations Project in late 2006 to assess the feasibility of improving survey-based measures of consumers' inflation and wage expectations. ${ }^{1}$ Our project to date

\footnotetext{
${ }^{1}$ The number of consumer surveys has increased markedly around the world during the past decade. To improve the overall quality of the available data, several central banks have launched their own surveys of inflation expectations or have contracted with third parties to develop and conduct new surveys on their behalf.
} 
has had two components: an assessment of the usefulness of the Michigan survey's questions on inflation expectations, and the development and implementation —on an experimental basisof an alternative survey of household expectations.

In this edition of Current Issues, we describe the structure of our project in more detail and present early results. Our assessment of the Michigan Survey confirms the existence of certain limitations: We find that the wording of the questions invites differing interpretations, that respondents have no means to express uncertainty about future inflation, and that the survey format elicits little or no information about wage expectations or the process by which respondents form and revise their inflation expectations.

Our effort to develop and implement an alternative survey also yields important findings. A question asking directly about the "rate of inflation" rather than "prices in general" leads to a measure of expected future inflation outcomes that is more informative and less susceptible to diverse interpretations. We also confirm earlier findings of differences in inflation expectations across demographic groups and document marked changes in the size of these differences over time. Our new measure of the uncertainty of consumers' inflation expectations indicates that uncertainty has declined considerably since mid-2008, while disagreement among respondents-a commonly used proxy for uncertainty-increased sharply during much of the sample period. Finally, our measure of wage expectations reveals a persistent expectation that real wages will decline. ${ }^{2}$

\section{The Household Inflation Expectations Project}

The Household Inflation Expectations Project is a unique collaboration among Federal Reserve research staff, academic economists, and psychologists at Carnegie Mellon University who specialize in behavioral decision making as well as risk perception and communication. The project's main goals are 1) to assess the information content of the Michigan Survey and the validity of its measures, 2) to improve the quality of existing surveys and to better align the measurement of household inflation expectations with the central role that inflation expectations play in the formation and communication of monetary policy, 3) to improve the understanding of how consumers form and update inflation expectations, and 4) to assess the links between inflation expectations and consumer behavior.

The project to date has been structured in three stages. The first two stages - preliminary inquiries conducted through phone and Internet surveys - gauged how individuals interpreted the Michigan Survey questions and how they would respond to alternative questions about future inflation. The Internet survey also "piloted" questions on wage expectations and inflation uncertainty to expand the information currently elicited by the Michigan Survey. These preliminary inquiries guided the final formulation of the questions for the third stage of our project- the actual implementation of an alternative survey of household inflation expectations. ${ }^{3}$

\footnotetext{
2 See van der Klaauw et al. (2008) for a fuller account of our findings.

${ }^{3}$ Note that, by design, the number and identity of our respondents differed from one stage to the next.
}

\section{Motivation for the Project}

A major impetus for the HIEP was the recognition, shared by many economists, policymakers, and survey modelers, that the Michigan Survey and other existing surveys of inflation expectations had significant limitations.

Wording of Questions Can Yield Different Interpretations. A feature of the Michigan and similar surveys is their use of simplified wording. For example, they ask about "prices in general" rather than the "rate of inflation." Studies of survey design suggest that the use of simplified language provides no assurance that all respondents will interpret a question in the same way_or in a way that would be of interest to policymakers (see Bruine de Bruin [forthcoming] and Schwarz [1999]). Indeed, asking about prices in general leads respondents to think more about particular price changes that may figure prominently in their own experience than about changes in the overall price level. Moreover, when respondents focus on price changes specific to their own experience, they may tend to pay more attention to price changes that are larger (rather than smaller) and that reflect increases (rather than decreases), especially for products purchased often (Bates and Gabor 1986; Jungermann et al. 2007; Ranyard et al. 2008).

Point Forecasts Do Not Measure Inflation Uncertainty. Many surveys of inflation expectations ask only for point forecasts of inflationthat is, single-value estimates. However, consumers' decisions may be affected not only by the expected level of inflation, but also by uncertainty about future inflation. ${ }^{4}$ To capture consumers' uncertainty about inflation outcomes, survey modelers can elicit "density forecasts." In a density forecast, respondents convey expectations in the form of a histogram by assigning probabilities to different possible outcomes.

Information on Wage Expectations Is Insufficient. Surveys of inflation expectations capture little, if any, information about wage expectations. Yet wage expectations, like inflation expectations, affect consumers' decisions about consumption and leisure across different periods and are thus of great value for understanding and forecasting economic behavior. ${ }^{5}$ Moreover, because price-setting behavior by firms depends at least partly on firms' total labor costs, wage dynamics are an important determinant of expected and actual inflation.

Surveys Provide Limited Information about How Expectations Are Formed. Existing surveys provide scant insight into how individuals form and update their expectations about future inflation. Yet such knowledge would be of great value to monetary policymakers: As argued by Bernanke (2007), "a fuller understanding of the public's learning rules would improve the central bank's capacity to assess its own credibility, to evaluate the implications of its policy decisions and communications strategy, and perhaps to forecast inflation."

One way to evaluate how expectations are revised is to track the responses of the same group of individuals over time. Such a

\footnotetext{
${ }^{4}$ For a discussion of alternative ways in which inflation uncertainty affects economic decision making and welfare, see Golob (1994).

${ }^{5}$ Bernanke (2007) stresses the importance of collecting better information on wage expectations.
} 
"panel" dimension, however, is absent from most surveys of inflation expectations. The Michigan Survey does have a panel element, but it is very limited: A subset of the respondents to the survey (roughly 200 of the 500 individuals polled) are reinterviewed - but only once and only after an interval of six months. These follow-up interviews yield only limited data on which to base conclusions about how or why individuals modify their inflation expectations.

\section{Project Structure}

We began the Household Inflation Expectations Project in the summer of 2007 by holding a set of open-ended, semi-structured "cognitive interviews" - interviews that elicit information about how respondents interpret questions and arrive at a response. The cognitive interviews, conducted by telephone, examined how respondents interpreted both the Michigan Survey's question about expected changes to "prices in general" and a set of alternative questions about inflation expectations.

This first stage of our project revealed that interviewees had diverse interpretations of the Michigan Survey question about "prices in general." Some saw it as asking about inflation, while others believed it was asking about specific prices they paid, particularly for food and gasoline. By contrast, interviewees were less likely to think of specific prices they had paid when asked for their expectations about the "rate of inflation." In addition, we learned that interviewees often wanted to report ranges rather than point forecasts of inflation, suggesting the presence of uncertainty in their forecasts.

These findings helped determine our choice of alternative questions for measuring inflation expectations - specifically, our decision to pose questions about the "rate of inflation" as well as questions about "the prices of things you usually spend money on." To find out whether the results of our phone interviews with a small number of people would hold for a larger group, we initiated the second stage of our project, which involved the construction of survey "modules," or sets of questions, to be added to the American Life Panel (ALP). The ALP — an existing Internet survey conducted by the RAND Corporation - served as our vehicle for contacting respondents. Our survey modules, administered to about 700 people, asked respondents to interpret the Michigan question about "prices in general" and our alternative question about the "rate of inflation." In addition, the modules included a preliminary set of questions that invited respondents to systematically express their expectations about wage changes as well as their uncertainty about their forecasts for both price inflation and wage inflation. ${ }^{6}$

\footnotetext{
${ }^{6}$ The survey modules were designed in collaboration with a team of behavioral psychologists from Carnegie Mellon University led by Wändi Bruine de Bruin and Baruch Fischhoff. Providing valuable input were Michael Bryan of the Federal Reserve Bank of Atlanta; Olivier Armantier of the Federal Reserve Bank of New York; Andrew Levin and Arthur Kennickell of the Board of Governors of the Federal Reserve System; academic consultants Charles Manski, Kenneth Wolpin, and Eric Johnson; and a team from the RAND Corporation's Roybal Center for Financial Decision Making led by Jeff Dominitz and Arie Kapteyn. All modules were pilot-tested on small samples by the Carnegie Mellon team.
}

The third stage of our project, the implementation of our survey of household expectations, built upon the earlier phone and Internet inquiries. The survey instrument contained our new questions in their final form and also included, for comparison, the main Michigan Survey questions. The American Life Panel again served as the vehicle for this final set of queries, referred to as the "FedALP Panel" hereafter. The sample population consisted of Michigan Survey respondents who agreed to take part in further surveys after completing the Michigan questionnaire. Our survey, launched in November 2007, has been administered to this same group roughly every six weeks.

\section{Main Findings to Date}

\section{Wording of Questions}

Reliable measurement requires that respondents agree with one another - and with economic modelers — on what the survey questions mean. If respondents vary in their interpretation of a question, their responses may display more disagreement than they otherwise would. Indeed, one feature that the Michigan Survey's question about "prices in general" shares with other surveys is a high dispersion of responses around the median. This evidence of disagreement is in part related to observable characteristics of respondents such as age, gender, education, and income (see Bryan and Venkatu [2001a,b]). However, the differences in response across demographic groups far exceed the variations in inflation experienced by the groups (see Hobijn et al. [2009]), and may reflect some ambiguity in the question.

Moreover, a large number of Michigan Survey respondents typically expect changes in "prices in general" to far exceed recently observed inflation rates. For example, from May to July 2008, 25 percent of the respondents expected price changes greater than or equal to 10 percent over the next twelve months. Other surveys have asked questions about past (realized) changes in prices and found that some of the dispersion of views about future price changes is associated with the dispersion of views about past price changes.

When we asked our respondents about expected changes to "prices in general" (the Michigan Survey question), we found that a significant fraction believed we were inquiring about the prices they paid themselves - often prices that had increased or decreased markedly, such as those for food or gasoline (Bruine de Bruin et al. 2010a). This tendency to think more about prominent price changes in one's own experience is particularly common among respondents with lower financial literacy (Bruine de Bruin et al. 2010b). By contrast, when we asked about expectations for the "rate of inflation," respondents tended to think less about a few salient price changes specific to their own experience and more about price changes across a broader set of items - a result that aligns more with economists' definition of inflation as a sustained increase in the overall price level.

Although it was rated as somewhat more difficult to answer than the "prices in general" question, our alternative question about the "rate of inflation" had only a slightly higher (by less than 1 percent) 
nonresponse rate and elicited expectations that were less strongly correlated with price expectations for gas and food. In addition, the question generated less disagreement, as indicated by the smaller interquartile range of the distribution of responses across participants. The interquartile range-essentially, the range of the middle 50 percent of responses - is a reliable measure of dispersion. ${ }^{7}$ In this case, the smaller range suggests that respondents interpreted our question in a more consistent way than the Michigan Survey question. Our question also generated lower overall forecast uncertainty, as measured by the median (across individuals) of the density forecasts' interquartile range. This finding holds across different time horizons with respect to expectations for both near- and long-term inflation expectations as well as for perceptions of past inflation. ${ }^{8}$

\section{Forecast Uncertainty}

The ability to measure and monitor movements in inflation uncertainty is important for several reasons. Recent communications from the Federal Reserve, the European Central Bank, and other central banks have discussed upside or downside risks to the economic outlook, highlighting the need for quantitative risk measures to be included in the policymaker's toolkit.

Furthermore, by tracking inflation uncertainty, a central bank can assess its credibility and the effectiveness of its communications. An increase in uncertainty about future inflation outcomes may be an early warning of eroding central bank credibility. Mishkin (2008) has suggested that a central bank may want to view the costs of inflation in terms of both its level and its uncertainty. To the extent that uncertainty about future inflation affects consumers' decisions, measuring that uncertainty is of direct interest to policymakers because of the relevance for tracking and forecasting economic conditions.

Our survey has successfully implemented a probability-based version of the various alternative questions about inflation expectations that takes the form of a density forecast. ${ }^{9}$ Questions about density forecasts and questions about point forecasts had similarly high response rates. Density forecasts were also consistent with other responses. For example, we find respondents' uncertainty about future inflation realizations to be positively correlated with their use

\footnotetext{
${ }^{7}$ The interquartile range is defined as the difference between the 75th and the 25th percentiles of a distribution and is less sensitive to extreme views (outliers) than are other measures of dispersion, such as the variance.

${ }^{8}$ The Fed-ALP Panel also asked for respondents' medium-term expectations (three years ahead) for the "rate of inflation." This time horizon was chosen for consistency with typical macroeconomic modeling of medium-term responses to shocks. Expected inflation and inflation uncertainty over the medium term may be important indicators for assessing the credibility of monetary policy objectives and the effectiveness of central bank communication.

${ }^{9}$ We use a format similar to that employed in the Federal Reserve Bank of Philadelphia's Survey of Professional Forecasters and the Bank of Italy's Survey of Household Income and Wealth. To begin, we define several possible "bins" for the rate of inflation (for example, 0 percent to 2 percent, ..., 12 percent or higher). We then ask respondents to assign probabilities - the "percentage chance" - to these predefined bins (see Bruine de Bruin et al. [2009] for details). Thereafter, we fit a probability density to each respondent's reported histogram.
}

of a range rather than a single value to report their forecast and with the width of the reported range. ${ }^{10}$

Our results also indicate that disagreement between respondents, as captured by the dispersion in their point forecasts, is not always a good proxy for uncertainty about future inflation. ${ }^{11}$ We measure disagreement as the interquartile range of the distribution of point forecasts across respondents, and median forecast uncertainty as the median (across respondents) of the interquartile range of an individual respondent's density forecast. As a measure, median forecast uncertainty describes a "typical" respondent's uncertainty about future inflation. As we observe below, disagreement and uncertainty about median forecasts exhibit very different patterns over time in our Fed-ALP Panel.

\section{Wage Expectations}

Because firms and workers may negotiate wage changes in line with their expectations for inflation, data on wage expectations provide an additional source of information for analyzing inflation dynamics and the interaction between wage and price determination. Furthermore, discrepancies between expected changes in wages and expected inflation may affect households' financial decisions.

Unfortunately for economic analysts, information on wage expectations is particularly scarce. To address this deficit, our survey includes questions that ask respondents to report their expectations for wage changes in the form of both point and density forecasts. Not surprisingly, respondents have found the question asking for a point forecast of the expected wage change to be clearer and easier to answer than questions asking for their expectations of the rate of inflation or of changes to prices in general. During the Fed-ALP Panel survey period of November 2007 to November 2009, respondents expected wages to rise significantly less than prices (that is, they expected a decline in real wages) and they expressed less uncertainty about future wage changes than about future price changes.

\section{Dynamics of Inflation Expectations}

To better understand the process by which individuals form and update their inflation expectations, we conduct repeat surveys - at intervals of about six weeks - with the same panel of respondents. Our findings point to considerable persistence in inflation expectations and in uncertainty over time. We observe that those who are more uncertain are likelier to make greater (absolute) revisions to their point forecasts, a result suggesting that their estimates are more volatile. More details on observed patterns over time are given below.

\section{Current Patterns over Time}

Here we present trends for several of our measures of inflation expectations over the 2007-09 Fed-ALP Panel survey period. These trends

\footnotetext{
${ }^{10}$ See Bruine de Bruin et al. (2009) for additional findings on internal consistency and the reliability of our uncertainty measure.

${ }^{11}$ Examining point and density forecasts of inflation from the Survey of Professional Forecasters, Rich and Tracy (2010) find little support for the use of disagreement as a proxy for uncertainty.
} 
Chart 1

\section{Trends in Forecast Quartiles for "Prices in General" By Income Level}

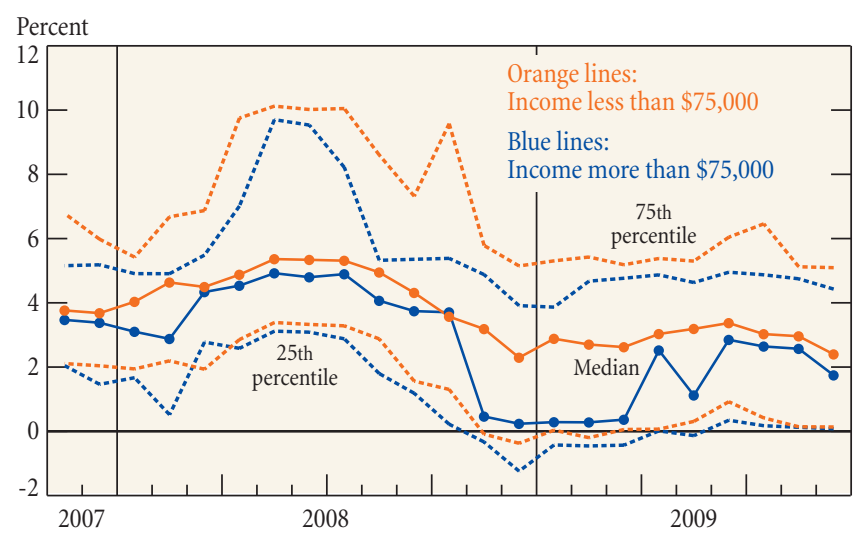

Source: Reuters/University of Michigan Survey of Consumers.

Note: Shown are quartiles of the distribution of individuals' point forecasts.

are of clear interest to policymakers, providing insight into the recent evolution of expectations about future price and wage inflation.

\section{Point Forecasts}

Recall that the "prices in general" question elicits responses that exhibit considerable differences across individuals in both levels and trends. Trends in year-ahead point forecasts in the Michigan Survey vary significantly with respondents' income levels (Chart 1). Lower income respondents report significantly higher and more dispersed expectations, as captured by the 25th and 75th percentiles of the forecast distribution for each group.

Part of this difference across income groups appears to reflect fundamental differences in beliefs, and could therefore be important to track. At the same time, additional evidence from our own survey indicates that at least some of the differences across demographic groups are attributable to variation in financial literacy. Part of this variation, in turn, relates to how much respondents think of salient prices they pay when forming their expectations; respondents who have lower financial literacy think more about such prices. ${ }^{12} \mathrm{Com}$ pared with expectations for "prices in general," expectations for the "rate of inflation" reveal a different time pattern for the median forecast of year-ahead inflation (Chart 2), one that is generally lower and less variable over time. Moreover, they show a less dramatic increase during the gasoline price spike of 2008 as well as a smaller decline during the gasoline price drop at the end of that year.

\section{Disagreement and Uncertainty}

Year-ahead expectations for the "rate of inflation" decrease over the sample period (Chart 3); in fact, we see a fairly pronounced decline in expectations from the levels during the summer of 2008 through

${ }^{12}$ For more on the findings associated with financial literacy, see Bruine de Bruin et al. (2010b).
Chart 2

Median Year-Ahead Forecasts for "Prices in General" and "Rate of Inflation"

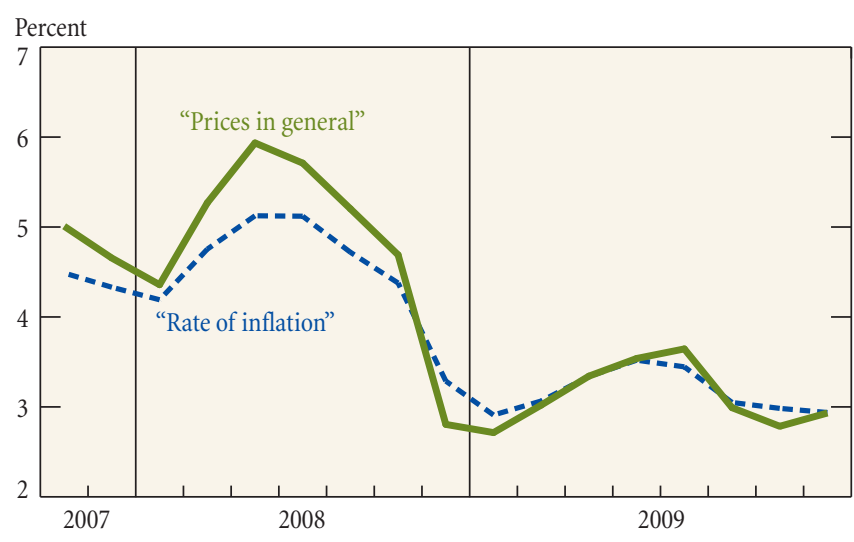

Source: Fed-ALP Panel.

Note: Shown are medians of individuals' point forecasts of year-ahead changes.

Chart 3

Year-Ahead Expectations for "Rate of Inflation"

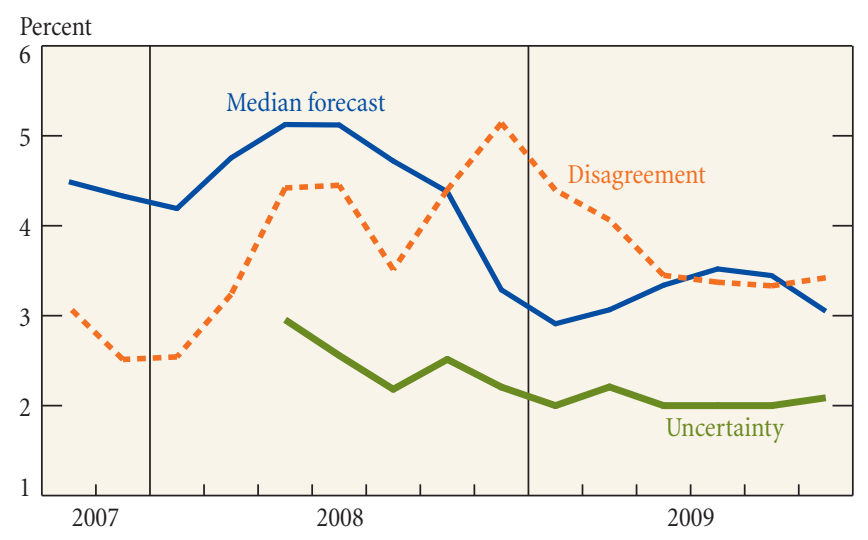

Source: Fed-ALP Panel.

Notes: The median forecast is the median of individuals' point forecasts; disagreement is the interquartile range of individuals' point forecasts. Uncertainty is measured as the sample median of individuals' density interquartile ranges for year-ahead "rate of inflation," a measure available only since June 2008.

year-end. The decrease likely reflects the combination of falling prices for energy and other commodities as well as a large amount of economic slack during that episode. Over the same sample period, disagreement shows a considerable increase until the end of 2008, after which it begins a decline almost back to pre-crisis levels.

Disagreement is especially high during the summer of 2008 and reaches a peak that December - a spike that coincides with the federal funds rate nearing its lower bound of zero. ${ }^{13}$ In contrast,

\footnotetext{
${ }^{13}$ At that time, debates in the business media were quite lively, with some commentators stressing a potential deflation risk and others expressing concern about high inflation.
} 
Chart 4

\section{Year-Ahead Expectations for "Rate of Inflation" Quartiles by Income Group}

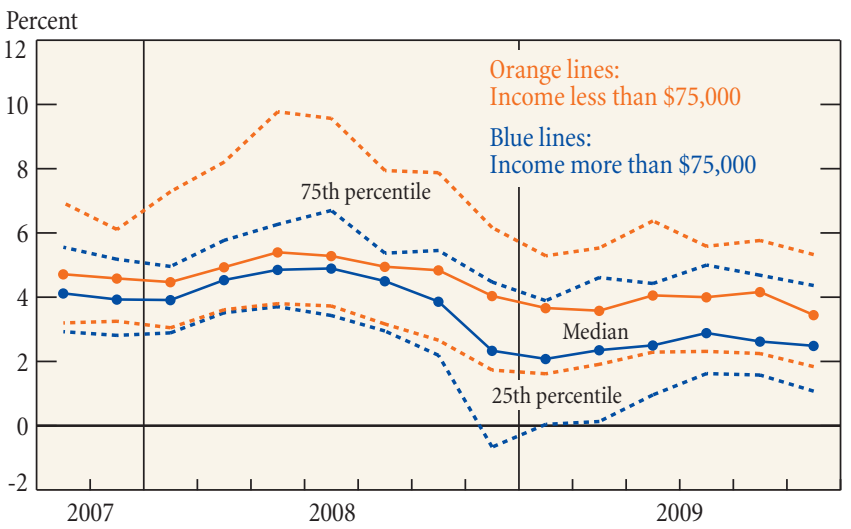

Source: Fed-ALP Panel.

Note: Shown are 25th and 75th percentiles of the distribution of individuals' point forecasts.

inflation uncertainty falls steadily in the sample period (measures are available only starting in June 2008) and displays little variability around and since December 2008. Thus, there is little evidence of a meaningful relationship between disagreement and uncertainty.

Other interesting features of the data emerge when we examine "rate of inflation" expectations across income groups, differentiating between high- and low-income respondents. Chart 4 presents the median inflation forecast and the 25th and 75th percentiles of the forecast distribution for each group (with the difference between percentiles representing our measure of disagreement for each group), while Chart 5 depicts median inflation uncertainty for each group. We derive several findings of note. First, disagreement is generally higher within the low-income group. Second, as December 2008 approaches, inflation expectations diverge across income groups, owing mainly to an increased concern about low inflationor even deflation - expressed by high-income respondents. Third, disagreement across high-income respondents is marked and persistent beginning in December 2008, but disagreement among those of low income spikes in the summer of 2008 and then falls to pre-crisis levels. We observe very little change in forecast uncertainty within each group during the same period. In fact, median forecast uncertainty actually declines beginning in the fall of 2008 .

Interestingly, two distinct views emerged around the time when the federal funds rate approached its lower bound of zero: While the high-income group displayed a marked increase in concern about the risk of deflation, the low-income group generally maintained its concern about ongoing inflation. In addition, a considerable polarization in views occurred within the high-income group, as disagreement more than doubled between September and December 2008 and became comparable to that of the low-income group.

\section{Chart 5 Uncertainty about Year-Ahead "Rate of Inflation"
By Income Group}

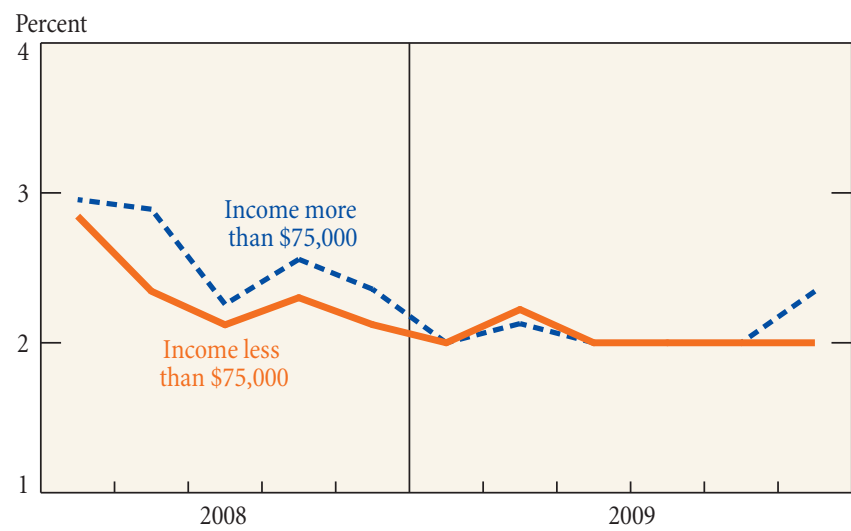

Source: Fed-ALP Panel.

Note: Shown are sample medians of individuals' density interquartile ranges that correspond to density forecasts for year-ahead "rate of inflation," a measure available only since June 2008.

Chart 6

\section{Trends in Expectations for Wage Growth and Wage Uncertainty, One Year Ahead}

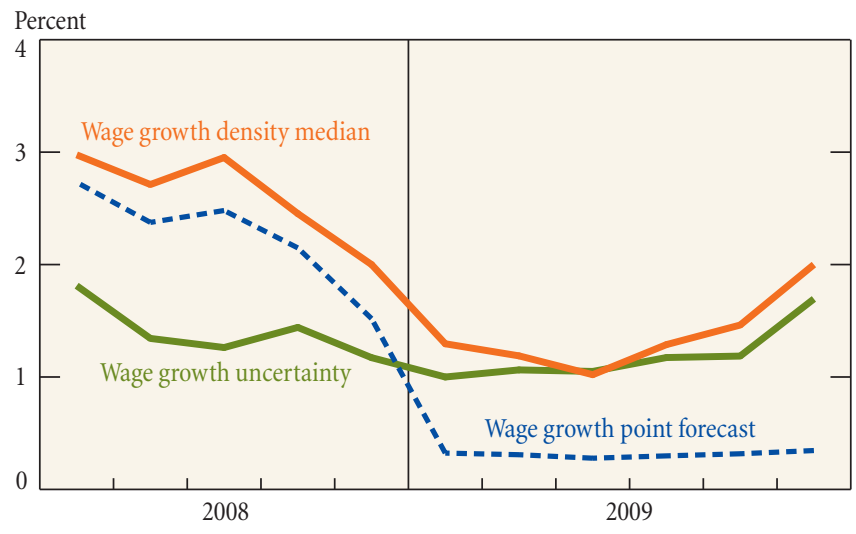

Source: Fed-ALP Panel.

Notes: Shown are medians of individuals' point and density forecasts. Uncertainty is measured as the sample median of individuals' density interquartile ranges for year-ahead wage growth.

The decline in forecast uncertainty points to a firming of views within both income groups, with each expressing increasingly strong convictions about its forecasts. In the second half of 2009, deflation concerns seem to diminish within the high-income group, but the gap in median inflation expectations between the two income groups persists.

\section{Wage Expectations}

The recent decline in year-ahead inflation expectations has been paralleled by a decline in expectations for wage growth (Chart 6). Whether gauged by the median of point forecasts or the median of 
individual density forecasts, expectations for wage growth have been consistently below inflation expectations over the survey period, implying that most respondents expect an ongoing decline in real wages.

Individual point forecasts of wage growth have been persistently lower than density medians, especially since the beginning of 2009 . The density forecasts show a recent increase in expected wage growth, while the individual point forecasts continue to indicate zero growth. Finally, while uncertainty about future wage growth has remained relatively stable over the entire sample period, our most recent survey indicates that such uncertainty is showing a noticeable increase.

\section{Conclusion}

A key goal of the Household Inflation Expectations Project has been the development of improved survey measures of inflation expectations. While we believe that our new survey measures will enhance the ability of policymakers to monitor key aspects of consumer inflation expectations, much remains to be learned about how consumers form and act on their expectations. In future research, we hope to go beyond direct measurement to pursue two paths.

First, we plan to learn more about the way in which households form and update their expectations, the speed and manner in which expectations respond to price changes and other new information, and the role and effects of monetary policy announcements and other public sources of information. Second, we expect to study the links between inflation expectations and consumer behavior, such as purchases of housing and other big-ticket items, mortgage refinancing, credit card debt management, investment in human capital (for example, student loans), and wage negotiation.

This work will shed further light on the processes by which households form and update their expectations, which in turn may assist us in designing survey questions that enable respondents to express expectations more accurately. Such research will also be helpful in predicting how consumers respond to specific price changes and other new information as well as to economic and financial developments. The speed and possible heterogeneity of the updating process across individuals can be critical for a central bank as it seeks to forecast responses to policy actions and other events.

\section{References}

Bates, John M., and André Gabor. 1986. "Price Perception in Creeping Inflation; Report on an Enquiry." Journal of Economic Psychology 7, no. 3: 291-314.
Bernanke, Ben S. 2007. "Inflation Expectations and Inflation Forecasting." Presentation to the Monetary Economics Workshop of the National Bureau of Economic Research Summer Institute, July 10. Available at http://www.federalreserve.gov/ newsevents/speech/bernanke20070710a.htm.

Bruine de Bruin, Wändi. Forthcoming. "Framing Effects in Surveys: How Respondents Make Sense of the Questions We Ask." In Gideon Keren, ed., Perspectives on Framing. London: Taylor and Francis.

Bruine de Bruin, Wändi, Charles F. Manski, Giorgio Topa, and Wilbert van der Klaauw. 2009. "Measuring Consumer Uncertainty about Future Inflation." Federal Reserve Bank of New York Staff Reports, no. 415, December.

Bruine de Bruin, Wändi, Wilbert van der Klaauw, Julie S. Downs, Baruch Fischhoff, Giorgio Topa, and Olivier Armantier. 2010a. "The Effect of Question Wording on Reported Expectations and Perceptions of Inflation." Federal Reserve Bank of New York Staff Reports, no. 443, April.

.2010b. "Expectations of Inflation: The Role of Demographic Variables, Expectation Formation, and Financial Literacy." Journal of Consumer Affairs 44, no. 2 (summer): 381-402.

Bryan, Michael F, and Guhan Venkatu. 2001a. "The Demographics of Inflation Opinion Surveys." Federal Reserve Bank of Cleveland Economic Commentary, October 15.

.2001b. "The Curiously Different Inflation Perspectives of Men and Women." Federal Reserve Bank of Cleveland Economic Commentary, November.

Golob, John E. 1994. “Does Inflation Uncertainty Increase with Inflation?” Federal Reserve Bank of Kansas City Economic Review 79, no. 3 (third quarter): 27-38.

Hobijn, Bart, Kristin Mayer, Cartier Stennis, and Giorgio Topa. 2009. "Household Inflation Experiences in the U.S.: A Comprehensive Approach." Unpublished paper, Federal Reserve Bank of New York.

Jungermann, Helmut, Hans W. Brachinger, Julia Belting, Katarzyna Ginsberg, and Elizabeth Zacharias. 2007. "The Euro Changeover and the Factors Influencing Perceived Inflation." Journal of Consumer Policy 30, no. 4 (December): 405-19.

Mishkin, Frederic S. 2008. "Whither Federal Reserve Communications." Presentation to the Peterson Institute for International Economics, July 28. Available at http://www.federalreserve.gov/newsevents/speech/mishkin20080728a.htm.

Ranyard, Rob, Fabio Del Missier, Nicolao Bonini, Darren Duxbury, and Barbara Summers. 2008. "Perceptions and Expectations of Price Changes and Inflation: A Review and Conceptual Framework." Journal of Economic Psychology 29, no. 4 (August): 378-400.

Rich, Robert, and Joseph Tracy. 2010. “The Relationships among Expected Inflation, Disagreement, and Uncertainty: Evidence from Matched Point and Density Forecasts." Review of Economics and Statistics 92, no. 1 (February): 200-7.

Schwarz, Norbert. 1999."Self-Reports: How the Questions Shape the Answers." American Psychologist 54, no. 2 (February): 93-105.

van der Klaauw, Wilbert, Wändi Bruine de Bruin, Giorgio Topa, Simon Potter, and Michael Bryan. 2008. "Rethinking the Measurement of Household Inflation Expectations: Preliminary Findings." Federal Reserve Bank of New York Staff Reports, no.359, December.

\section{ABOUT THE AUTHORS}

Wändi Bruine de Bruin is an assistant professor in the Department of Social and Decision Sciences and the Department of Engineering and Public Policy at Carnegie Mellon University; Simon Potter is director of economic research at the Federal Reserve Bank of New York; Robert Rich is an assistant vice president in the Bank's Macroeconomic and Monetary Studies Function; Giorgio Topa is an assistant vice president and Wilbert van der Klaauw a vice president in the Microeconomic and Regional Studies Function.

The views expressed in this article are those of the authors and do not necessarily reflect the position of the Federal Reserve Bank of New York or the Federal Reserve System. 